\title{
An Investigation of Cross-Cultural Teaching of the Non-English Majors in Hexi University
}

\author{
Jun Zhang \\ School of Foreign Language, China West Normal University, Nanchong, Sichuan, China.
}

\begin{abstract}
As the establishment of the status of English as a universal language, a new requirement has been put forward in college English teaching in China, which is to cultivate high-quality talents with intercultural communicative competence. However, college English teaching in our country is in language knowledge-centered for a long-term, paying attention to the cultivation of students' language competence, but ignoring cultural learning, which seriously affects the cultivation of students' intercultural ability. In order to truly reflect the current situation of cross-cultural teaching in college English, and to find out specific problems and causes in cross-cultural teaching in college English, this paper takes Hexi University for an example and analyzes it.
\end{abstract}

Key words: cross-cultural teaching; Hexi University; non-English majors

\section{Introduction}

Globalization has strengthened ties and cooperation among different countries, and has also provided a platform for communication between different cultural values and social structures (Liang Lanfang and Liu Qihong, 2006: 55). The emergence and development of each language has its specific social and historical environment, and this social and historical environment are bound to be reflected in the language (Wang Kaiyu, 2003: 24). As a country that a large amount of people tend to learn English, China has paid attention to deal with breakdown in communication with native-speakers due to lack of appropriate cross-cultural knowledge (Bai Wenxia, 2016: 1). And Kramsch (1993: 55) advocated the multicultural interactive mode of language and cross-cultural teaching, this model breaks through the simple input of cultural teaching in the past, exerts equal stress on mother tongue and target language, forms a two-way interaction, and corrects the phenomenon that the former emphasizes on cultural teaching content and ignores cultural teaching process.

\section{A Questionnaire Survey on Cross-Cultural Teaching in Hexi University}

In this chapter, more detailed things on this questionnaire will be paid more attention so as to know the current situation of cross-cultural teaching for non-English majors. And it will be divided into two main parts: one is questionnaire design and implementation, the other is about questionnaire statistics and analysis.

2.1 Questionnaire design and implementation

Quantitative research method will be adopted for this chapter.

\subsubsection{Respondents}

The respondents, who are from different colleges, are all between the ages of 19 to 21.66 girls and 74 boys help the author to finish the questionnaires. Almost all of them are freshmen and sophomores who's English proficiency are all 
below CET 4.

\subsubsection{Questionnaire design}

The design of this questionnaire is closely related to the cognitive, emotional and behavioral aspects of the intercultural communicative competence model.

\subsubsection{Questionnaire implementation}

After collecting all the questionnaires, the author began to do the statistics analysis with using excel.

2.2 Questionnaire statistics and analysis

A total of 150 questionnaires were sent out, 140 were withdrawn and 140 valid papers were obtained.

\subsubsection{Statistics of students' opinions about culture}

Figure 1 which is used to illustrate the first question in the second part has been showed below. It is clear that a large number of respondents choose $\mathrm{A}, \mathrm{C}$ and $\mathrm{F}$. Therefore, it can be said that when it comes to contents of culture, national media, movies, literature and arts, local customs, traditional culture and history are the most important contents in respondents' points of view.

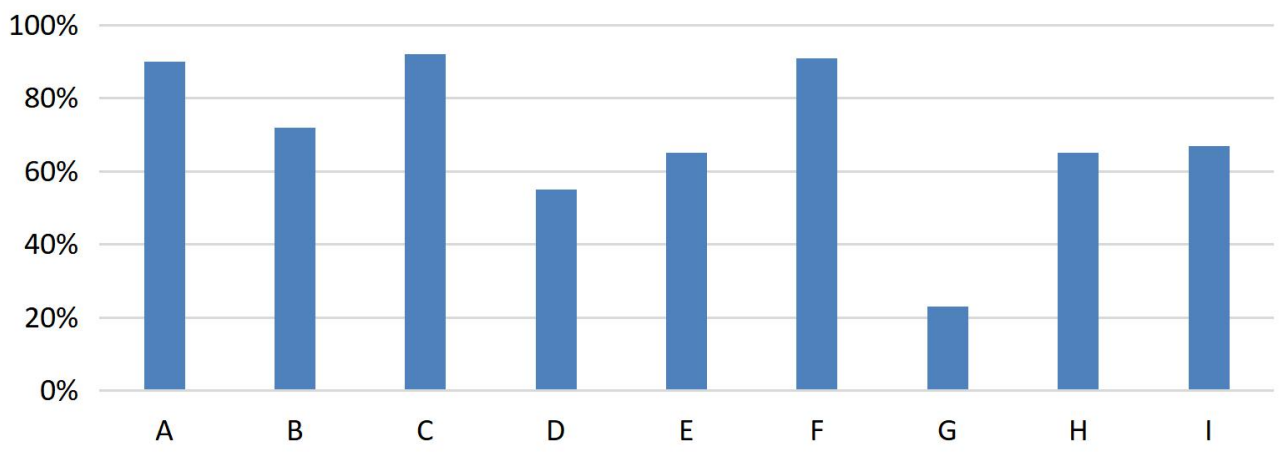

A: National media, movies, literature and arts

B: Relationships and family features and life among people

C: Local customs and traditional culture

D: Daily life and work of people

E: Eating and dressing

\section{F: History \\ G: Politics \\ H: Religion \\ I: Beliefs and attitudes of people}

Figure 1. Opinions about the content of culture

Figure 2 which is used to illustrate the second question in the second part has been showed below. So respondents think that views on values, social interaction and religious customs are a little bit more important than the other two aspects when it comes to the contents of cross-cultural communication.

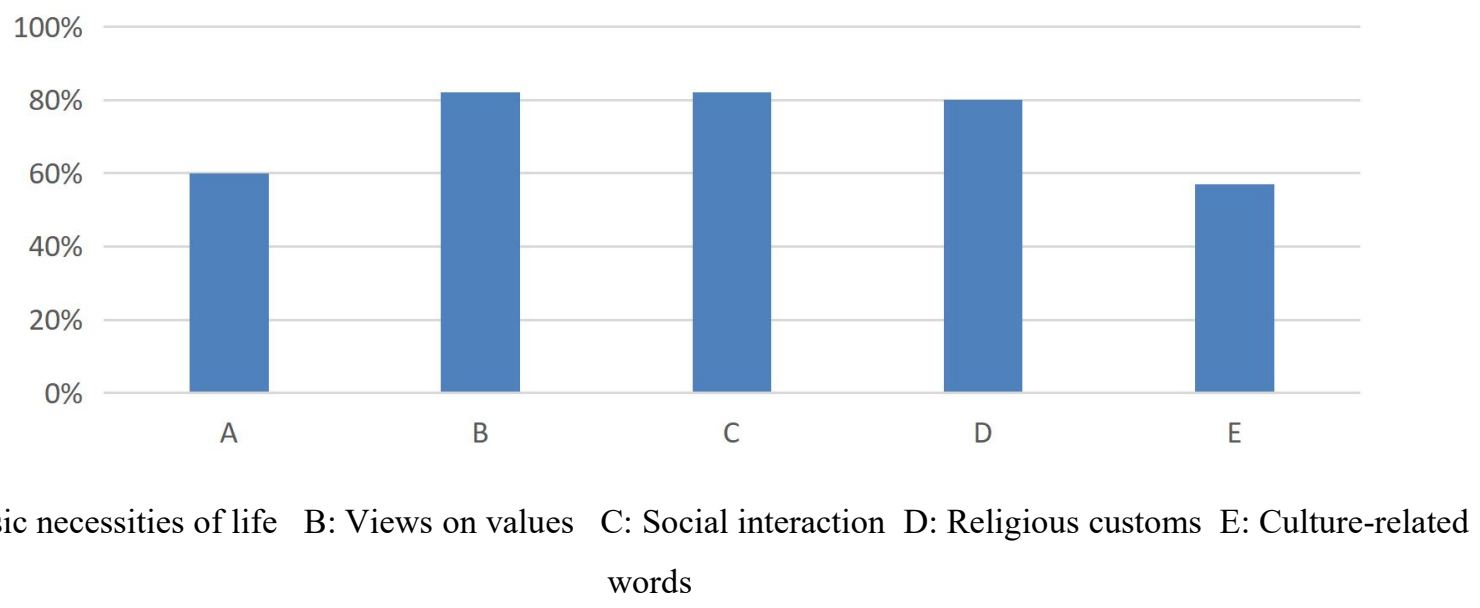

Figure 2. Including contents of cross-cultural communication 
Figure 3 which is used to illustrate the third question in the second part has been showed below. Through this figure, obviously the respondents think that they can know something about cross-cultural knowledge through TV program, online news, literature works and newspaper.

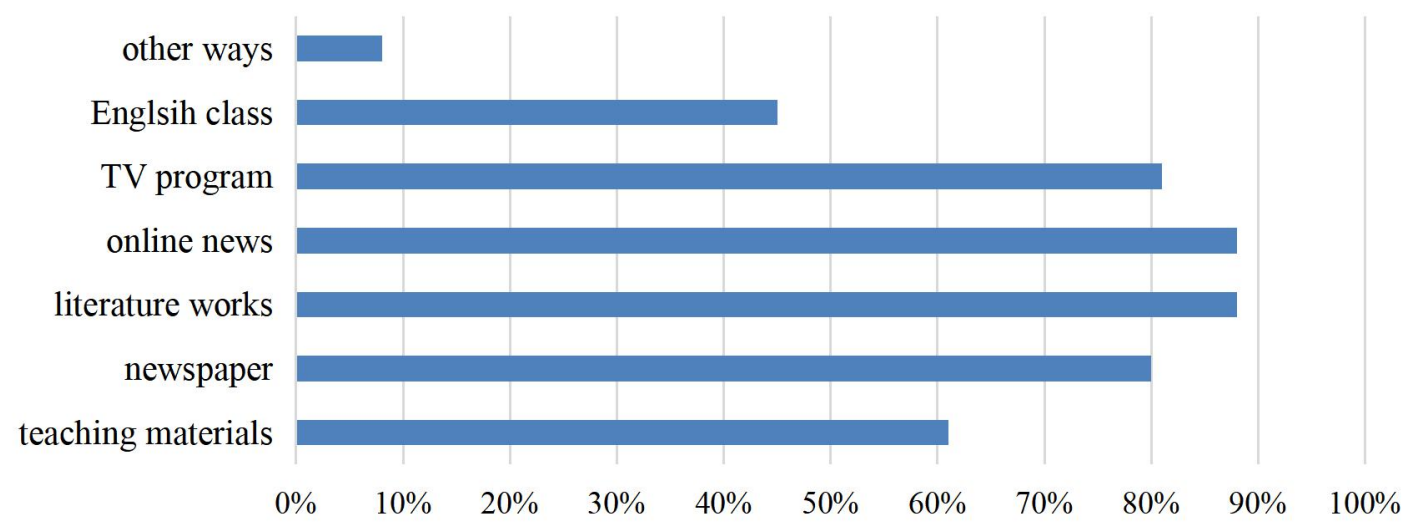

Figure 3. Sources of knowing cross-cultural knowledge

\subsubsection{Statistics of students' views on English and cultural learning}

The third part is to investigate students' views on English learning and cultural learning. Respondents are asked to make choices among completely agree, agree, uncertain, disagree and completely disagree.

Table 1. The specific number of respondents for each option

\begin{tabular}{|c|c|c|c|c|c|}
\hline & CA & A & U & D & CD \\
\hline $\mathbf{1 .}$ & 32 & 95 & 12 & 0 & 1 \\
\hline $\mathbf{2 .}$ & 21 & 94 & 16 & 8 & 1 \\
\hline $\mathbf{3 .}$ & 23 & 97 & 13 & 7 & 0 \\
\hline $\mathbf{4 .}$ & 38 & 84 & 14 & 4 & 0 \\
\hline $\mathbf{5 .}$ & 34 & 92 & 12 & 1 & 1 \\
\hline $\mathbf{6 .}$ & 38 & 81 & 18 & 3 & 0 \\
\hline $\mathbf{7 .}$ & 30 & 89 & 16 & 5 & 0 \\
\hline
\end{tabular}

Table 1 shows that the number of respondents who choose each option in each question $(\mathrm{CA}=$ completely agree, $\mathrm{A}=$ agree, $\mathrm{U}=$ uncertain, $\mathrm{D}=$ disagree, $\mathrm{CD}=$ completely disagree). So 127 of them think that cross-cultural learning plays an important role in English learning. And 115 of them think that it should include some cultural knowledge of other countries in English tests. When it comes to whether cross-cultural learning should be set in English teaching or not, there are 120 of them say yes. 122 of them think that their confidence can be enhanced through cross-cultural learning. And 126 of them think cross-cultural learning can improve their language competence. 119 of them think an excellent English teaching model must stay with the purpose of improving students' communication competence. 119 of them think that cross-cultural learning can increase their interests for English learning.

In a word, it is quite clear that a large number of respondents have positive attitudes towards cross-cultural communication and think that cross-cultural learning can really make sense.

Table 2 shows the situation of question 8-12 which talk about some negative aspects about cross-cultural learning have something different from question 1-7. The eighth question talks about the reason why they are not interested in cross-cultural knowledge is that it's not involved in the exams, 47 of them agree, while 93 of them are uncertain or 
disagree. 54 of them agree that they don't have enough time to learn cross-cultural knowledge due to other language skills that need to acquire. 43 of them think that it's possible for people who learn about some culture of other countries to give rise to some bias towards those countries. And 68 of them think that it is not easy for them to acquire some cross-cultural knowledge in English classroom. For the twelfth question which talks about whether cross-cultural learning is important for learning English well or not. 70 of them think it's not important or uncertain.

Table 2. The specific number of respondents for each option

\begin{tabular}{|c|c|c|c|c|c|}
\hline & CA & A & U & D & CD \\
\hline $\mathbf{8 .}$ & 8 & 39 & 42 & 34 & 17 \\
\hline $\mathbf{9 .}$ & 8 & 46 & 33 & 15 & 38 \\
\hline $\mathbf{1 0 .}$ & 7 & 36 & 36 & 43 & 18 \\
\hline $\mathbf{1 1 .}$ & 12 & 56 & 38 & 8 & 26 \\
\hline $\mathbf{1 2 .}$ & 7 & 33 & 30 & 20 & 50 \\
\hline
\end{tabular}

\subsubsection{Statistics of current situation of cross-cultural teaching in college English course}

Figure 4 which is used to illustrate the first question in the third part has been showed below, and it is to investigate how much attention teachers pay to cross-cultural teaching. Through this figure, $34 \%$ of students think that their teachers pay more attention to it, and $13 \%$ of them think teachers pay a little bit attention to it, $51 \%$ of them think their teachers pay a lot of attention to it, while $2 \%$ of them think their teachers don't care it.

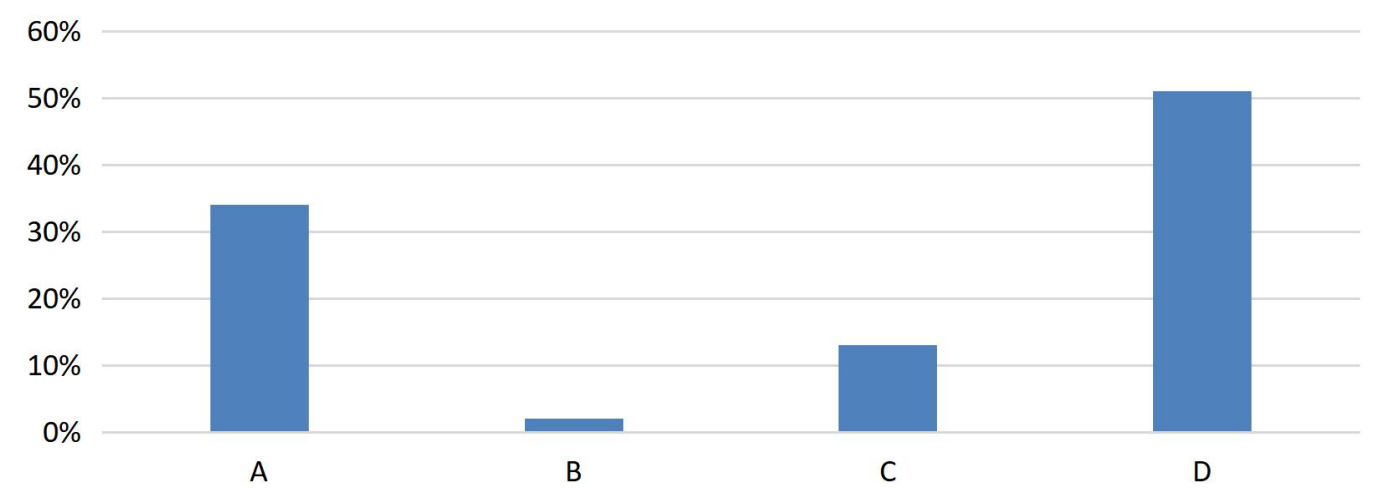

A: More attention B: No attention C: A little bit attention D: More attention

Figure 4. Attention teachers pay to cross-cultural teaching

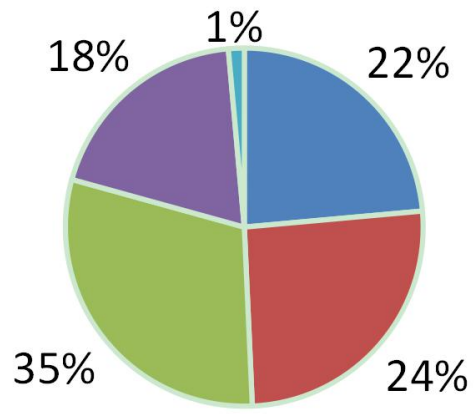

20 mins $\square 15$ mins 10 mins $\square$ less than 10 mins $\square$ zero

Figure 5. The time spent in cross-cultural teaching in every class 
Figure 5 investigates about the time spent in cross-cultural teaching in every class. $81 \%$ of their teachers spend more than 10 minutes on cross-cultural teaching, while $19 \%$ of them spend less than 10 minutes.

Figure 6 is about the number of parts which are included in teaching materials are introduced by teachers. In a word, obviously, college English teachers pay a little attention to cross-cultural teaching, and it's not enough for students' to acquire some cross-cultural communication skills.

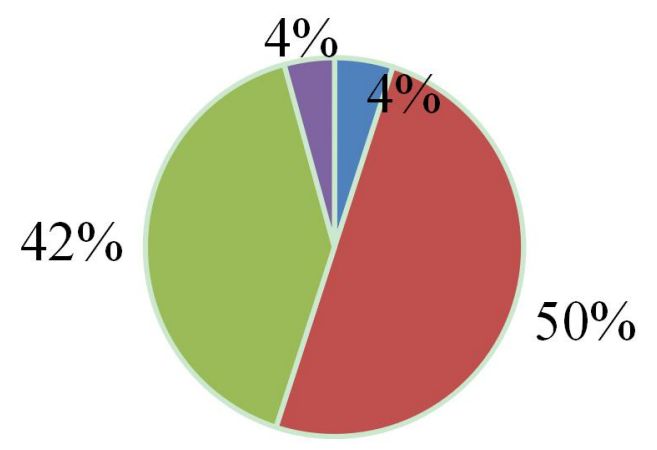

Figure 6. The number of parts introduced by teachers

Figure 7 talks about students' attitudes towards cross-cultural teaching and asks them whether cross-cultural teaching is important or not. $53 \%$ of them think cross-cultural teaching has a little bit importance for them and $27 \%$ of them have no idea or think it's not a big deal, while $20 \%$ of them think it is very important to them.

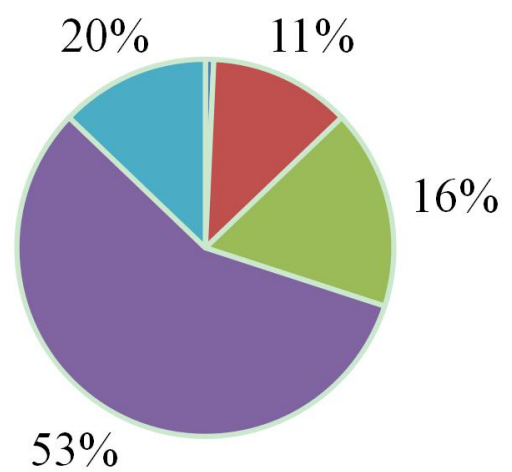

Figure 7. Students attitudes towards cross-cultural teaching

Figure 8 talks about students' interests in some activities of cross-cultural teaching. $90 \%$ of them are interested in classroom activities related to cross-cultural teaching and $10 \%$ of them are not. Therefore, it is clear that students' learning motivation exists.

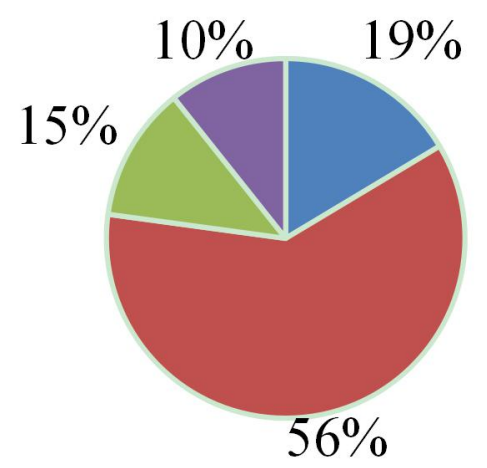

Figure 8. Students' interests in activities of cross-cultural teaching 
Figure 9 talks about activities that English teachers usually adopt in classroom and students can choose more than one option. $66 \%$ of teachers adopt multimedia and movies in cross-cultural English classes, 22\% of them adopt role-play, $18 \%$ of them adopt drawings, and only $3 \%$ of them adopt other ways.

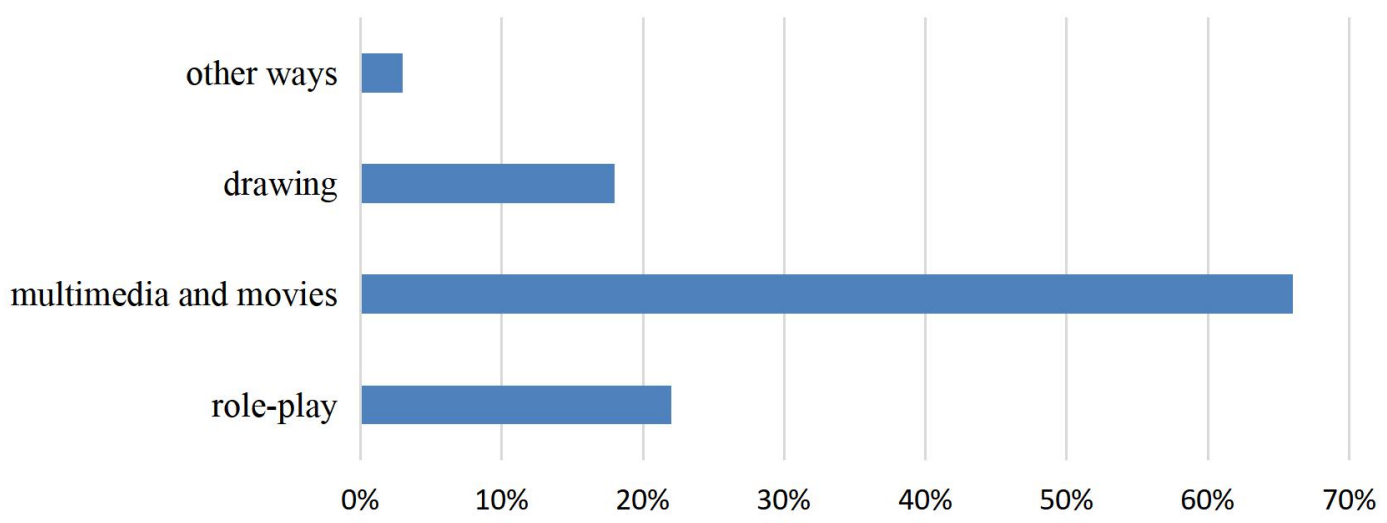

Figure 9. Activities English teachers adopt in classroom

Figure 10 is to investigate teaching methods teachers usually adopt in English classroom to cultivate students' crosscultural competence and students can choose more than one option. And $68 \%$ of students think emphasizing so much words related to cultures of other countries is the most commonly adopted teaching methods by their teachers, $55 \%$ of their teachers introduce some cultural background knowledge of western countries.

$70 \%$
$60 \%$
$50 \%$
$40 \%$
$30 \%$
$20 \%$
$10 \%$
$0 \%$

A

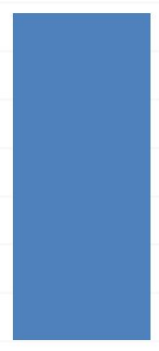

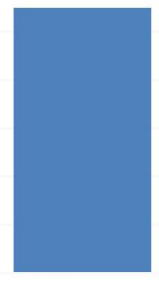

B

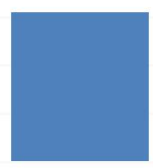

C

A: Words related to cultures of other countries B: Cultural background knowledge of other countries C: Differences between countries

Figure 10. Teaching methods the teachers adopt in English classroom

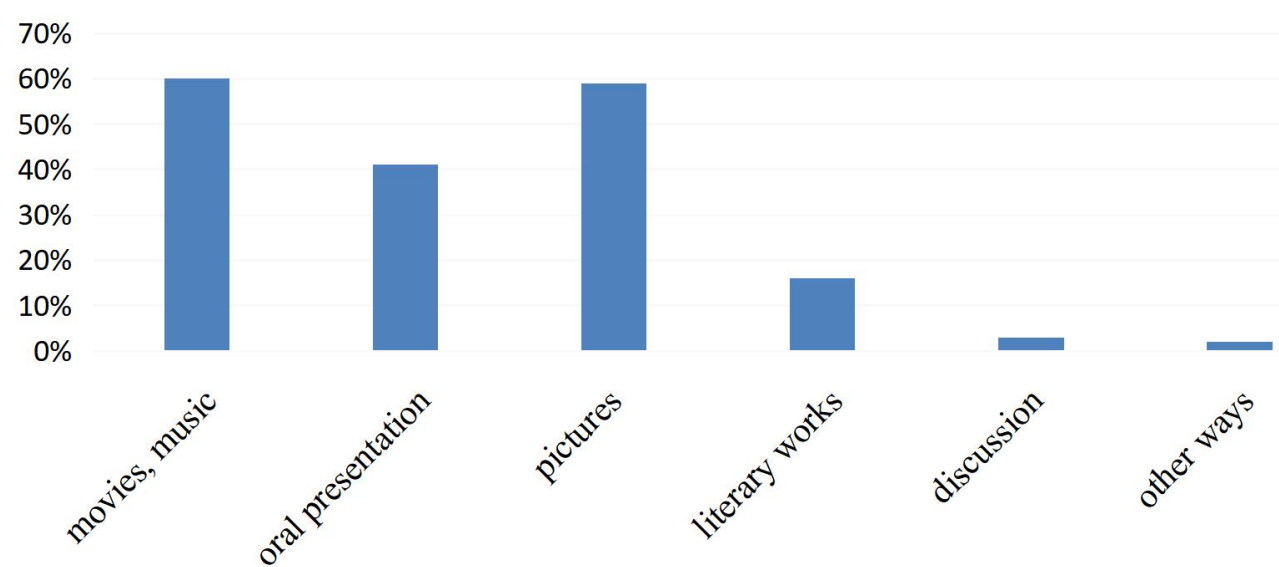

Figure 11. Ways teachers use to impart cross-cultural knowledge 
Figure 11 talks about how teachers impart cross-cultural knowledge to students in English classroom and students can choose more than one option. $60 \%$ of students are taught by a movie, a piece of music and $58 \%$ of them use pictures to learn about some knowledge about culture. $42 \%$ of their teachers introduce some cross-cultural knowledge by oral presentation.

Figure 12 is to investigate the number of cultural knowledge that are included in teaching materials. $2 \%$ of students think their teaching materials don't conclude anything related to cross-cultural knowledge and $68 \%$ of them think their teaching materials conclude appropriate contents.

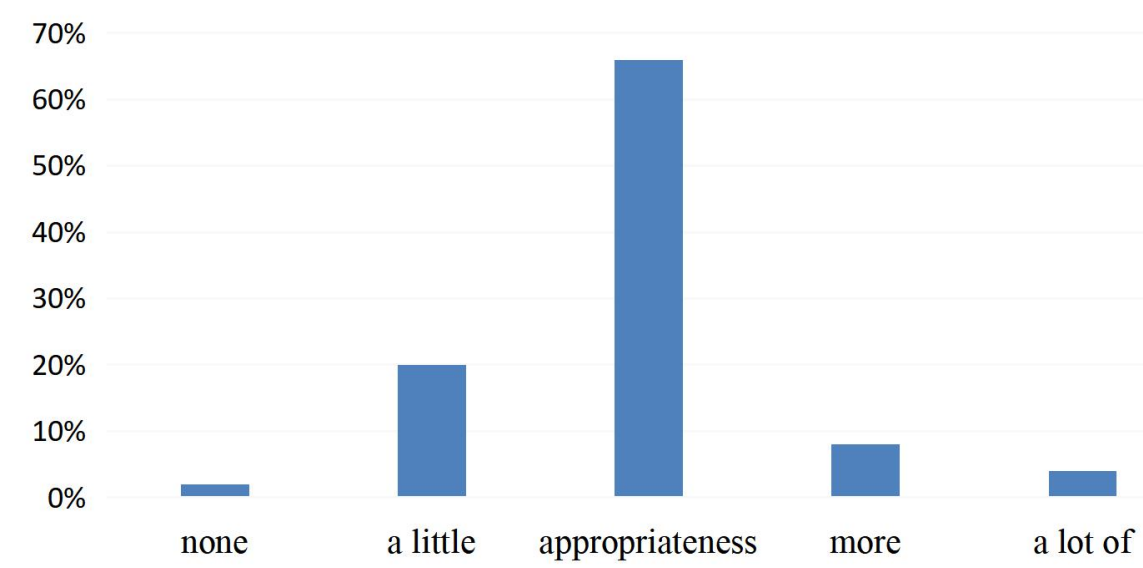

Figure 12. The number of cultural knowledge included in teaching materials

Figure 13 talks about the teaching contents of cross-cultural knowledge in teaching materials and students can choose more than one option. $56 \%$ of their teachers pass on some politic systems and traditional culture, and $61 \%$ of their teachers pass on some spiritual culture such as values and religion beliefs. $54 \%$ of them think that their teachers pay more attention to some background knowledge, and $40 \%$ of them think that their teachers pay attention to the differences between cultures.

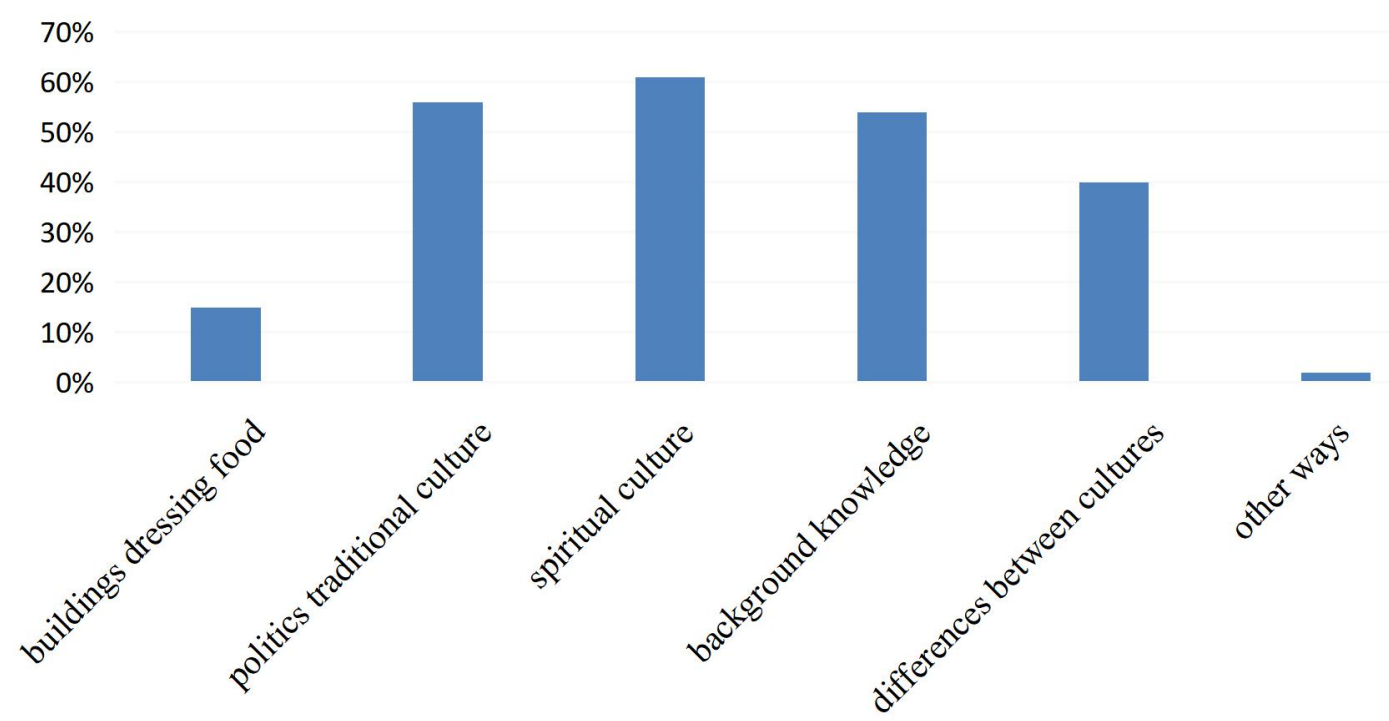

Figure 13. teaching contents of cross-cultural knowledge in teaching materials

Figure 14 is to investigate that how their teachers think of the importance of language skills and cultural knowledge. $42 \%$ of them think their teachers give priority to reading skills and culture knowledge is the second. $37 \%$ of them think 
reading skills and culture knowledge are both given priority. $8 \%$ of them think that their teachers only care about the reading skills. $2 \%$ of them think that their teachers only care about culture knowledge. And 3\% of them think their teachers give priority to culture knowledge and reading skills are the second.

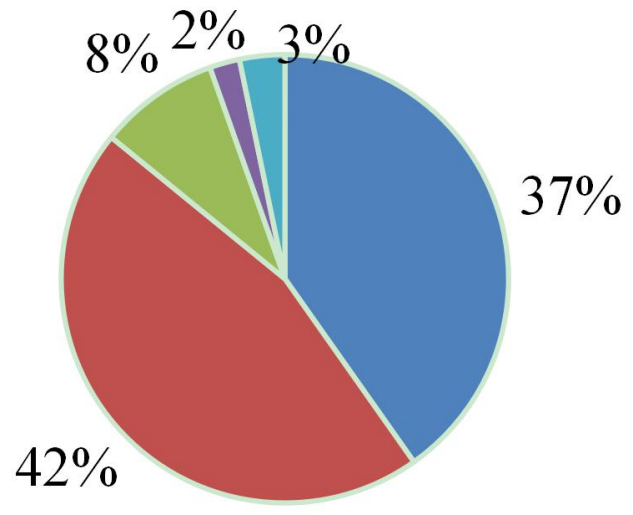

Figure 14. The importance of language skills and cultural knowledge

\section{Existing Problems in Cross-Cultural Teaching}

In view of the current situation of cross-cultural teaching for college students, college English teaching should focus on learning about social history, geographical features, culture and literature works of the target language countries, so as to improve students' cross-cultural communication competence in an all-round way (Liu Yingshuang, 2016: 115). However, from the last part which talks about questionnaire statistics and analysis, many problems have been surfaced.

\subsection{Lack of cross-cultural communication awareness among students}

The purpose of learning a language is to communicate (Oliver and Robert, 1962: 43), and English is not an exception. Students were educated on the special importance of words, sentence memorization and reading skills which were keys to get a good grade in English tests since they were kids. The result of this kind of learning sequence is that when language competence is improved to a certain level, cultural barriers become more prominent (Peng Bo, 2009: 15). To a certain extent, this is due to the influence of linguistic instrumentalism on people's understanding of language and their habit of teaching language only as a symbol (Chen Guiqin, 2013: 14).

\subsection{Low level of teachers' cross-cultural competence}

Teachers in exam-oriented education pay attention to cultivate students' reading skills, because these teachers are also trained from this mode of education. It seems that for language learning, the most important thing is how to get higher marks, rather than how to break cultural barriers and communicate with native-speakers (Ge Chunpin and Wang Shouren, 2016: 82). That's to say, teachers' own concept of language teaching has not changed, which means they consider English as a subject rather than a tool. College English teachers do not completely abandon cultural teaching, but are too simplistic in teaching content and teaching methods.

\subsection{Insufficiency of cross-cultural content in teaching materials}

Teaching material is the main carrier of teaching contents, and the main basis and guide for teachers and students to teach and to learn, and it is the key to cultivating students' intercultural communicative competence (Byram, 1989: 73). Starkey (2002: 50) pointed out that human rights education should be emphasized in cultural education, and moral education should also be included in it. 


\section{Effective Strategies to Improve Cross-Cultural Teaching}

In this chapter, some strategies to improve cultural teaching will be introduced from the perspective of students, teachers and teaching materials to match with existing problems.

4.1 To awake students' cross-cultural communication awareness

Students should also be encouraged to talk more with native-speakers and even make some foreign friends. More foreign teachers should be invited to the college English classrooms to have face-to-face communication with those students, because this kind of relaxed personal interaction will enable students to learn more about culture that they can't learn in classrooms.

4.2 To improve teachers' cross-cultural competence and the efficiency of teaching

Brooks emphasizes that cultural teaching should be included in the whole process of foreign language teaching, and teachers should determine different priorities and teaching methods at different stages (1968: 213). Teachers should pay attention to collecting, accumulating and making full use of foreign language cultural background knowledge and social customs (Kong Deliang and Luan Shuwen, 2012: 26). The teaching of background knowledge will not only make students have a deeper understanding of what they have learned, but also greatly promote teaching improvement of learning quality (Lin Ya, 2012: 126).

4.3 To improve the compilation of college English teaching materials

The content of cross-cultural teaching materials for college English should be arranged in terms of cultural themes. The compilation and selection of college English text books should reflect the characteristics of following times, filling with interests and culture, and the selected content should also be kept as original as possible in order to reflect cultural differences between China and the West (Wang Huoyan, 2012: 23).

\section{Conclusions}

College students are not only required to learn language itself, but also need to pay more attention to cultural learning. In this paper, questionnaire is adopted as a way to investigate the current situation of cultural teaching in Hexi University and try to find out some existing problems and give some recommended suggestions for those problems. 140 respondents who are all non-English majors in Hexi University help author finish questionnaires. With a careful statistics and analysis, some existing problems are found out, and some matched suggested strategies have been given. Obviously, it is impossible to solve these problems only to depend on someone, it needs to deal with them from different perspectives.

\section{Conflicts of Interest}

The author declares no conflicts of interest regarding the publication of this paper.

\section{References}

[1] Brooks N. (1968). Teaching Culture in the Foreign Language Classroom. Foreign Language Annuals, (3): 204217.

[2] Byram M. (1989). Cultural Studies in Foreign Language Education. Multilingual Matters, Clevedon, UK.

[3] Kramsch C. (1993). Context and Culture in Language Teaching. Oxford University Press, Oxford.

[4] Oliver and Robert T. (1962). Culture and Communication: The Problem of Penetrating National and Cultural Boundaries. Charles C. Thomas, Springfield.

[5] Starkey H. (2002). Democratic Citizenship, Languages, Diversity and Human Rights. Council of Europe, Strasbourg.

[6] Bai W.X. (2016). Research on the Status Quo of the Intercultural Communicative Competence of Non-English Major University Students. Tianjin Normal University, Tianjin. 
[7] Chen G.Q. (2013). An Empirical Study of College English Intercultural Teaching: Problems and Countermeasures

-- Based on a Case Study of Heilongjiang University of Science and Technology. Shanghai International Studies University, Shanghai.

[8] Ge C.P. and Wang S.R. (2016). The Cultivation of Intercultural Communicative Competence and College English Teaching. Foreign Language and Foreign Language Teaching, (2): 79-86.

[9] Liang L.F. and Liu Q.H. (2006). The Cultural Education in College English Education. Theory and Practice of Education, (8): 55-57.

[10] Lin Y. (2012). The Enlightenment of American Multicultural Education on College English Culture Education in China. Frontiers, (20): 124-126.

[11] Liu Y.S. (2016). The Stagnation and Transformation of College English Cross-cultural Education under the Background of Internationalization. Education Review, (7): 115-148.

[12] Kong D.L., Luan S.W. (2012). The Construction of Cross-cultural Teaching Mode of College English -Research Status and Theoretical Thinking. Foreign Language World, (2): 17-26.

[13] Pang B. (2009). The Cross Cultural Education in College English Teaching. Shandong Normal University, Jinan.

[14] Wang H.Y. (2012). A Study of College English Teaching Model Based on Intercultural Communication. Huazhong University of Science and Technology, Wuhan.

[15] Wang K.Y. (2003). Out of the language system: from "outside" to "inside" -- The Exploration of College English Teaching Based on Cross-cultural Education. Foreign Languages and Their Teaching, (12): 22-24. 